\title{
SHAPE MEMORY NiTi AND NiTiCu ALLOYS OBTAINED BY SPARK PLASMA SINTERING PROCESS
}

\section{Cristiana Diana CIRSTEA ${ }^{1, a^{*},}$ Magdalena LUNGU ${ }^{a}$, Alexander M. BALAGUROV ${ }^{b}$, Virgil MARINESCUa , Otilia CULICOV Gabriela Sbarcea ${ }^{a}$, Vasile CIRSTEA ${ }^{c}$}

\author{
aINCDIE ICPE-CA, Bucharest, Romania, \\ bJoint Institute for Nuclear Research Frank Laboratory of Neutron Physics, Dubna, Russia, \\ 'Military Equipments and Technology Research Agency,Clinceni, Romania \\ adiana.cirstea@icpe-ca.ro, 'amagdalena.lungu@icpe-ca.ro, ${ }^{a}$ marinescu_v@icpe-ca.ro, \\ agabi@icpe-ca.ro, bbala@nf.jinr.ru, bulicov@nf.jinr.ru cirstea_vasile@yahoo.com
}

Keywords: NiTi, NiTiCu, spark plasma sintering, precipitates

\begin{abstract}
The addition of $\mathrm{Cu}$ to near equiatomic NiTi shape memory alloys (SMAs) can provide some modifications of their shape memory properties by affecting their transformation behavior. The same effect was obtained in the case of $\mathrm{Ni}_{3} \mathrm{Ti}_{2}$ and $\mathrm{Ni}_{4} \mathrm{Ti}_{3}$ precipitates presence in the microstructure of NiTi. Also the substitution of $\mathrm{Cu}$ to NiTi alloys increases the hardness of the materials. This paper presents the microstructural and mechanical investigations of NiTi and $\mathrm{NiTiCu}$ alloys obtained by spark plasma sintering (SPS) process that represents a great potential for researchers as a new process for the fabrication of intermetallic compounds.
\end{abstract}

\section{Introduction}

Development of NiTi and NiTiCu alloys by different methods was studied intensively over the last years. The classic method for obtaining these materials by induction and arc melting process have some negative aspects, such as requiring multiple remelting to get homogeneous structure, oxygen and crucible contamination and need to perform a secondary process like forging to get the final shape [1,2]. By contrast, NiTi alloys with net final shape can be produced by non-conventional powder metallurgy (PM) methods such as self-propagating high temperature synthesis (SHS), hot isostatic pressing (HIP) and spark plasma sintering (SPS) $[3,4,5]$.

These processes can avoid the problems associated with casting, like segregation or extensive grain growth and have the added advantages of precise control of composition and easy realization of complex part shapes [5].

Success in forming dense bulk nanostructures stems from the use of two forms of activation sequentially: mechanical alloying (MA) by high-energy ball milling and field activation by the use of high-density currents [6]

The SPS process that relies on field activation is a newly developed synthesis and sintering process in which rapid powders densification can be obtained [7]. It is claimed that uses microscopic electric discharges between the particles under pressure [8]. This has been acknowledged to reduce significantly the synthesis and densification temperatures limiting the grain growth [6].

Changes in chemical composition above Ti-50at\%Ni cause precipitation. In NiTi alloys, characterizations of microstructural evolution have shown strong connection between $\mathrm{Ni}_{4} \mathrm{Ti}_{3}$ precipitation and martensitic transformations. The transformation path changes from B2-B19' into B2-R-B19' $[9,10]$ in Ni-rich NiTi alloys when $\mathrm{Ni}_{4} \mathrm{Ti}_{3}$ precipitates are present in the $\mathrm{B} 2$ matrix. The fine $\mathrm{Ni}_{4} \mathrm{Ti}_{3}$ precipitates increase the strength of the austenite and limit the degree of plastic 
deformation during martensitic transformation under temperature or load cycling. Thus, the martensitic transformation temperature can be adjusted by controlling the size and density of $\mathrm{Ni}_{4} \mathrm{Ti}_{3}$ precipitates [11]. $\mathrm{Ni}_{4} \mathrm{Ti}_{3}$ precipitates strengthen the matrix by producing strain fields which improve shape memory recoverability. Compared to near-equiatomic NiTi alloys, Ni-rich SMAs can reach high hardness values after aging heat treatments due to the precipitation hardening mechanism and increasing the critical stress for slip.

Ternary element additions to NiTi SMA influence the transformation behavior, and thus allow adjustments for optimized performance. $\mathrm{Cu}$ is in particular interesting due to the following features (among others) [12]: narrowing the transformation temperature hysteresis, reducing the dependence of $\mathrm{M}_{\mathrm{s}}$ on the Ni:Ti ratio and influencing the type of transformation (B19 martensite or B19' martensite are dependent on $\mathrm{Cu}$-content) and associated elastic behavior.

The purpose of the present study is to examine the effect of mechanical alloying of a binary and ternary nickel-rich NiTi alloy with nominal composition of $51.5 \mathrm{at} \% \mathrm{Ni}-48.5 \mathrm{at} \% \mathrm{Ti}$ and $50 \mathrm{at} \% \mathrm{Ti}-$ $40 \mathrm{at} \% \mathrm{Ni}-10 \mathrm{at} \% \mathrm{Cu}$ with and without heat treatment in order to find out the correlation between resulted microstructure and mechanical properties.

\section{Experimental}

\subsection{Processing route of $\mathrm{NiTi}$ and $\mathrm{NiTiCu}$}

The NiTi and $\mathrm{NiTiCu}$ alloys were obtained by spark plasma sintering from NiTi and respectively, NiTiCu powders mixtures previously processed by mechanical homogenization (MH) or mechanical alloying (MA) to obtain a high degree of homogeneity. To obtained the desired chemical compositions for the NiTi and NiTiCu alloys presented in this study very pure and fine $\mathrm{Ni}$ (Merck, $10 \mu \mathrm{m}$ particle size), Ti (Merck, $150 \mu \mathrm{m}$ particle size) and $\mathrm{Cu}$ elemental powders (Merck, $<63 \mu \mathrm{m}$ particle size) were used. The mechanical homogenization was done in a glove box in protective atmosphere.

In the case of MA powders, accurately weighed $\mathrm{Ni}$ and $\mathrm{Ti}$ or $\mathrm{Ni}, \mathrm{Ti}$ and $\mathrm{Cu}$ powders were added to a vial-ball assemble that was placed in a planetary mono mill (Pulverisette 6, Fritsch $\mathrm{GmbH}$ ). Milling was done at room temperature in a stainless steel vial with stainless steel balls under an argon atmosphere. The balls to powder ratio was 7:1 at a rotation speed of $250 \mathrm{rpm}$ for a milling time of $15 \mathrm{~h}$. After that, to obtain different structural states, exhibiting different microstructures characteristics and mechanical properties, the NiTi and $\mathrm{NiTiCu}$ powders mixtures were processed by SPS in an installation of HP D25 type (FCT Systeme GmbH). The cylindrical samples with diameter of $20 \mathrm{~mm}$ and height of $4-5 \mathrm{~mm}$ were realized in vacuum by uniaxial pressing with 30 $\mathrm{MPa}$ at a sintering temperature of $850^{\circ} \mathrm{C}$ and holding time of 5 minutes. In order to increase the alloy homogeneity, on some NiTi samples has been applied a step sintering as follows: increasing with $100^{\circ} \mathrm{C} / \mathrm{min}$ until $850^{\circ} \mathrm{C}$, holding for $5 \mathrm{~min}$, cooling with $100^{\circ} \mathrm{C} / \mathrm{min}$ until $500^{\circ} \mathrm{C}$, holding for 5 min and cooling again at room temperature with $100^{\circ} \mathrm{C} / \mathrm{min}$ in high vacuum. The conditions for obtaining the samples are presented in Table 1.

Table 1. Technological parameters for achieving NiTi and NiTiCu samples

\begin{tabular}{|c|c|c|c|c|c|c|c|}
\hline \multirow[t]{2}{*}{$\begin{array}{l}\text { Samples } \\
\text { code }\end{array}$} & \multicolumn{3}{|c|}{$\begin{array}{l}\text { Composition } \\
\text { (wt. \%) }\end{array}$} & \multirow{2}{*}{$\begin{array}{c}\text { Mechanical } \\
\text { Alloying (MA) } \\
\text { (h) }\end{array}$} & \multicolumn{2}{|c|}{$\begin{array}{c}\text { Sintering temperature } \\
\left({ }^{\circ} \mathrm{C}\right)\end{array}$} & \multirow{2}{*}{$\begin{array}{c}\text { Holding } \\
\text { time } \\
\text { (min) }\end{array}$} \\
\hline & $\mathrm{Ni}$ & $\mathbf{T i}$ & $\mathrm{Cu}$ & & only sintering & with step sintering & \\
\hline A1 & 56.54 & 43.46 & & - & 850 & - & 5 \\
\hline $\mathrm{A} 2$ & 56.54 & 43.46 & & - & 850 & 500 & 5 \\
\hline $\mathrm{B} 1$ & 56.54 & 43.46 & - & 15 & 850 & - & 5 \\
\hline $\mathrm{B} 2$ & 56.54 & 43.46 & - & 15 & 850 & 500 & 5 \\
\hline S1 & 43.65 & 44.53 & 11.82 & - & 850 & - & 5 \\
\hline S2 & 43.65 & 44.53 & 11.82 & 15 & 850 & - & 5 \\
\hline
\end{tabular}

After each heat treatment, the samples were mechanically polished with 1200 grit $\mathrm{SiC}$ paper and $6,3,1 \mu \mathrm{m}$ diamond paste and $0.03 \mu \mathrm{m}$ colloidal silica to obtain mirror shine surfaces. 


\subsection{Characterization}

The NiTi and NiTiCu samples were characterized from the point of view of microstructural and mechanical properties by scanning electron microscopy (SEM) and energy dispersive X-ray (EDX) analyses, and nanoindentation testing, respectively.

To study the phases in the specimens, X-ray diffraction (XRD) was used with $\mathrm{Cu}$ Ka radiation at $40 \mathrm{kV}$ and a tube current of $30 \mathrm{~mA}$. The XRD measurements were taken over a $2 \mathrm{~h}$ range, from $10^{\circ}$ to $70^{\circ}$, using a step size of $0.02^{\circ}$.

SEM and EDX analyses were performed using a scanning electron microscope (Auriga, Carl Zeiss SMT). By SEM analysis was investigated the microstructure of the samples and by EDX analysis was determined the compositions of any existing phases in NiTi and NiTiCu materials.

Nanoindentation testing of NiTi and $\mathrm{NiTiCu}$ alloys was carried out using a nanohardness tester (CSM Instruments) under an indentation load of $500 \mathrm{mN}$ and a loading/unloading rate of 1000 $\mathrm{mN} / \mathrm{min}$ using a Berkovich diamond indenter. The analysis method of Oliver and Pharr was used [10] to determine Vickers hardness (HV) and Young's modulus (E). Eight measurements were made on each sample and the average results are presented further.

\section{Results and discussions}

\subsection{XRD, SEM and EDX characterizations}

In tables 2-7 are presented the XRD, EDX results and SEM microstructures of the A1, A2, B1, $\mathrm{B} 2, \mathrm{~S} 1$ and S2 samples. An examination of the X-ray diffraction patterns reveals at room temperature, with the peak position corresponding to the $\{110\} \mathrm{B} 22 \theta$ coordinate. This X-ray diffraction patterns suggest that the materials are of multiphasic type.

Also, in some X-ray diffraction spectra were searched some oxides, especially titanium ones. As it can be seen both from EDX analysis and diffraction spectrum were not identified such compounds. These oxides could occur in NiTi and $\mathrm{NiTiCu}$ materials during the operations for samples obtaining such as mechanical alloying or preparing samples for introduction into the SPS.

These results show that there are precipitates present in the microstructure of all the NiTi and NiTiCu samples. The precipitates are $\mathrm{Ni}_{2} \mathrm{Ti}, \mathrm{NiTi}_{2}, \mathrm{Ni}_{4} \mathrm{Ti}_{3}, \mathrm{Ni}_{3} \mathrm{Ti}_{2}$ and $\mathrm{Ni}_{3} \mathrm{Ti}$.

Table 2. EDX results, XRD spectrum and SEM microstructure of NiTi sample (A1) processed by SPS at $850^{\circ} \mathrm{C}$ for $5 \mathrm{~min}$

\begin{tabular}{|c|c|c|c|c|}
\hline \multirow{2}{*}{ Spectrum for $A 1$} & \multicolumn{2}{|c|}{ Composition (wt. \%) } & \multirow{2}{*}{ Phase } & XRD and SEM microstructure \\
\hline & $T i$ & $\mathrm{Ni}$ & & \\
\hline Spectrum 1 & 18.42 & 81.58 & $\mathrm{Ni}$ & Spectrum 10 \\
\hline Spectrum 2 & 46.72 & 53.28 & $\mathrm{NiTi}$ & 部: \\
\hline Spectrum 3 & 63.18 & 36.82 & $\mathrm{NiTi}_{2}$ & \\
\hline Spectrum 4 & 91.03 & 8.97 & $\mathrm{Ti}$ & \\
\hline Spectrum 5 & 91.43 & 8.57 & $\mathrm{Ti}$ & $y=$ \\
\hline Spectrum 6 & 62.68 & 37.32 & $\mathrm{NiTi}_{2}$ & \\
\hline Spectrum 7 & 3.45 & 96.55 & $\mathrm{Ni}$ & \\
\hline Spectrum 8 & 2.02 & 97.98 & $\mathrm{Ni}$ & \\
\hline Spectrum 9 & 22.12 & 77.88 & $\mathrm{Ni}_{3} \mathrm{Ti}$ & \\
\hline Spectrum 10 & 46.41 & 53.59 & $\mathrm{NiTi}$ & -2 \\
\hline
\end{tabular}

The XRD and EDX analysis showed that the structures of NiTi samples that were mechanically alloyed for 15 hours (B1, B2) have become more homogeneously comparatively with the samples $\mathrm{A} 1$ and A2, whose structures present undissolved $\mathrm{Ni}$ or Ti. This fact is confirmed by the results reported in binary NiTi alloys, showing that the driving force for the formation of $\mathrm{Ni}_{3} \mathrm{Ti}(\Delta \mathrm{H}=140$ 
$\mathrm{kJ} / \mathrm{mol})$ is stronger than that of $\mathrm{Ti}_{2} \mathrm{Ni}(\Delta \mathrm{H}=83 \mathrm{~kJ} / \mathrm{mol})$ and $\mathrm{TiNi}(\Delta \mathrm{H}=67 \mathrm{~kJ} / \mathrm{mol})$ [13]. Also, from the NiTi samples that suffered the second heat treatment at $500^{\circ} \mathrm{C}$ by SPS, only the B2 sample revealed $\mathrm{NiTi}_{2}, \mathrm{Ni}_{4} \mathrm{Ti}_{3}$ and $\mathrm{Ni}_{3} \mathrm{Ti}_{2}$ precipitates in its structure.

For the NiTiCu samples were obtained similar results both for mechanically alloyed (S2) and unalloyed (S1) samples, these being in agreement with the literature data [14, 15]. Also, the existence of a $\mathrm{Ti}_{2}(\mathrm{Ni}, \mathrm{Cu})$ phase can be attributed to the presence of a considerable amount of Tiregions in the amorphous phase produced during the milling process.

Table 3. EDX results, XRD spectrum and SEM microstructure of NiTi sample (A2) processed by step sintering

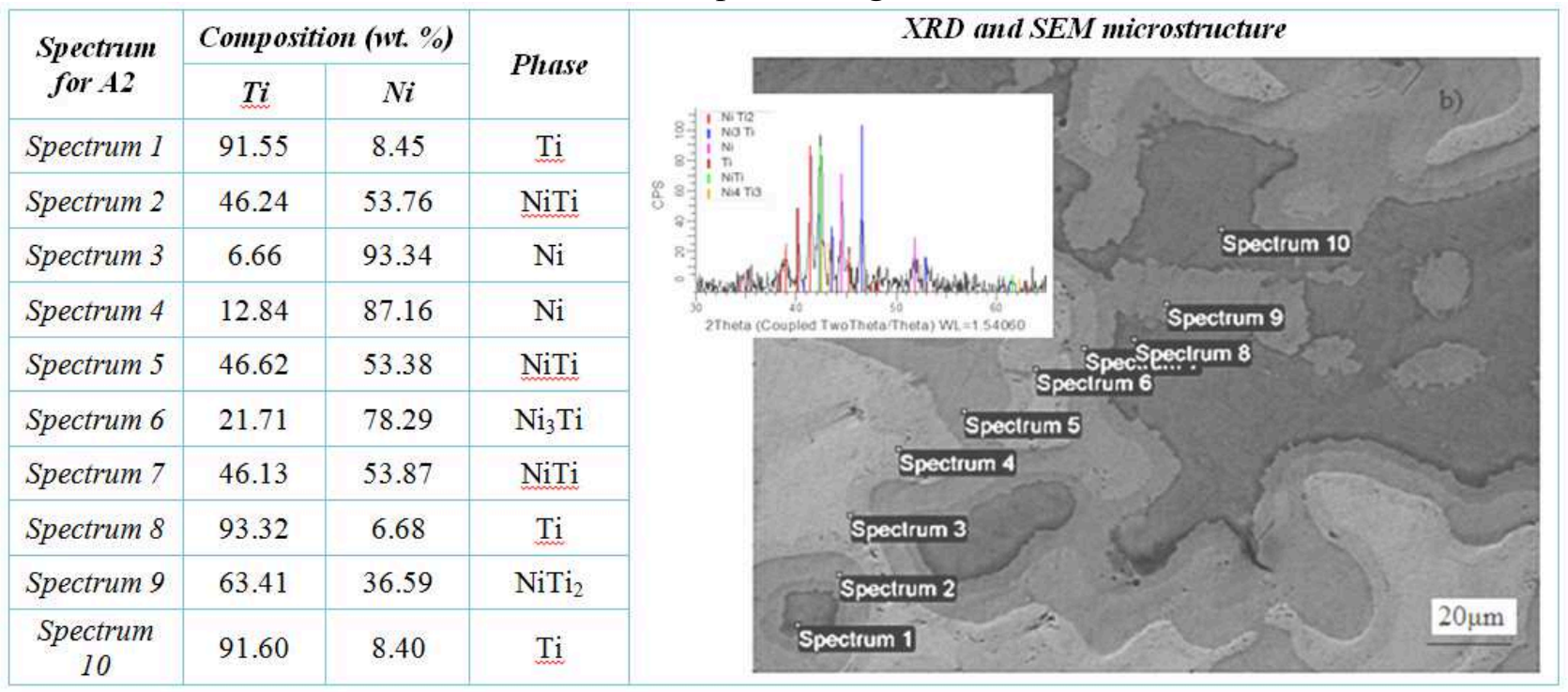

Table 4. EDX results, XRD spectrum and SEM microstructure of NiTi sample (B1) processed by MA and SPS

\begin{tabular}{|c|c|c|c|c|}
\hline \multirow{2}{*}{$\begin{array}{c}\text { Spectrum for } \\
B 1\end{array}$} & \multirow{2}{*}{\multicolumn{2}{|c|}{$\begin{array}{l}\text { Composition } \\
\text { (wt. \%) }\end{array}$}} & \multirow[b]{2}{*}{ Phase } & XRD and SEM microstructure \\
\hline & & & & 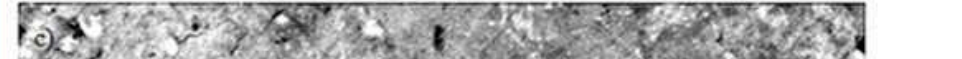 \\
\hline Spectrum I & 46.45 & 53.55 & $\mathrm{NiTi}$ & Yor \\
\hline Spectrum 2 & 31.86 & 68.14 & $\mathrm{Ni}_{2} \mathrm{Ti}$ & 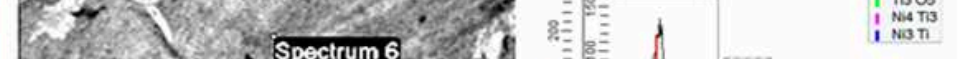 \\
\hline Spectrum 3 & 48.58 & 51.42 & NiTi & . \\
\hline Spectrum 4 & 45.92 & 54.08 & NiTi & 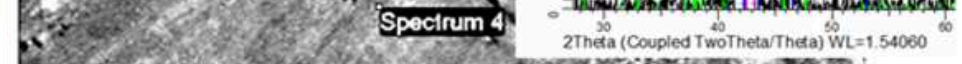 \\
\hline Spectrum 5 & 46.79 & 53.21 & NiTi & 18 \\
\hline Spectrum 6 & 47.33 & 52.67 & $\mathrm{NiTi}$ & $y$ \\
\hline
\end{tabular}


Table 5. EDX result, XRD spectrum and SEM microstructure of NiTi sample (B2) processed by MA and step sintering SPS

\begin{tabular}{|c|c|c|c|c|}
\hline \multirow{2}{*}{$\begin{array}{c}\text { Spectrum for } \\
\qquad 22\end{array}$} & \multicolumn{2}{|c|}{ Composition (wt. \%) } & \multirow{2}{*}{ Phase } & \multirow[t]{2}{*}{ XRD and SEM microstructure } \\
\hline & $T i$ & $\mathrm{Ni}$ & & \\
\hline Spectrum 1 & 49.84 & 50.16 & $\mathrm{NiTi}$ & 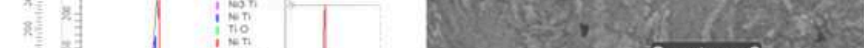 \\
\hline Spectrum 2 & 38.21 & 61.79 & $\mathrm{Ni}_{3} \mathrm{Ti}_{2}$ & $\delta^{\circ}$ \\
\hline Spectrum 3 & 43.73 & 56.27 & $\mathrm{Ni}_{4} \mathrm{Ti}_{3}$ & \\
\hline Spectrum 4 & 47.35 & 52.65 & $\mathrm{NiTi}$ & \\
\hline Spectrum 5 & 48.28 & 51.72 & $\mathrm{NiTi}$ & \\
\hline Spectrum 6 & 36.99 & 63.01 & $\mathrm{Ni}_{3} \mathrm{Ti}_{2}$ & \\
\hline Spectrum 7 & 49.62 & 50.38 & $\mathrm{NiTi}_{2}$ & $20 \mathrm{~mm}^{\mathrm{Spec}}$ \\
\hline
\end{tabular}

Table 6. EDX results, XRD spectrum and SEM microstructure of NiTiCu sample (S1) processed by SPS at $850^{\circ} \mathrm{C}$ for $5 \mathrm{~min}$

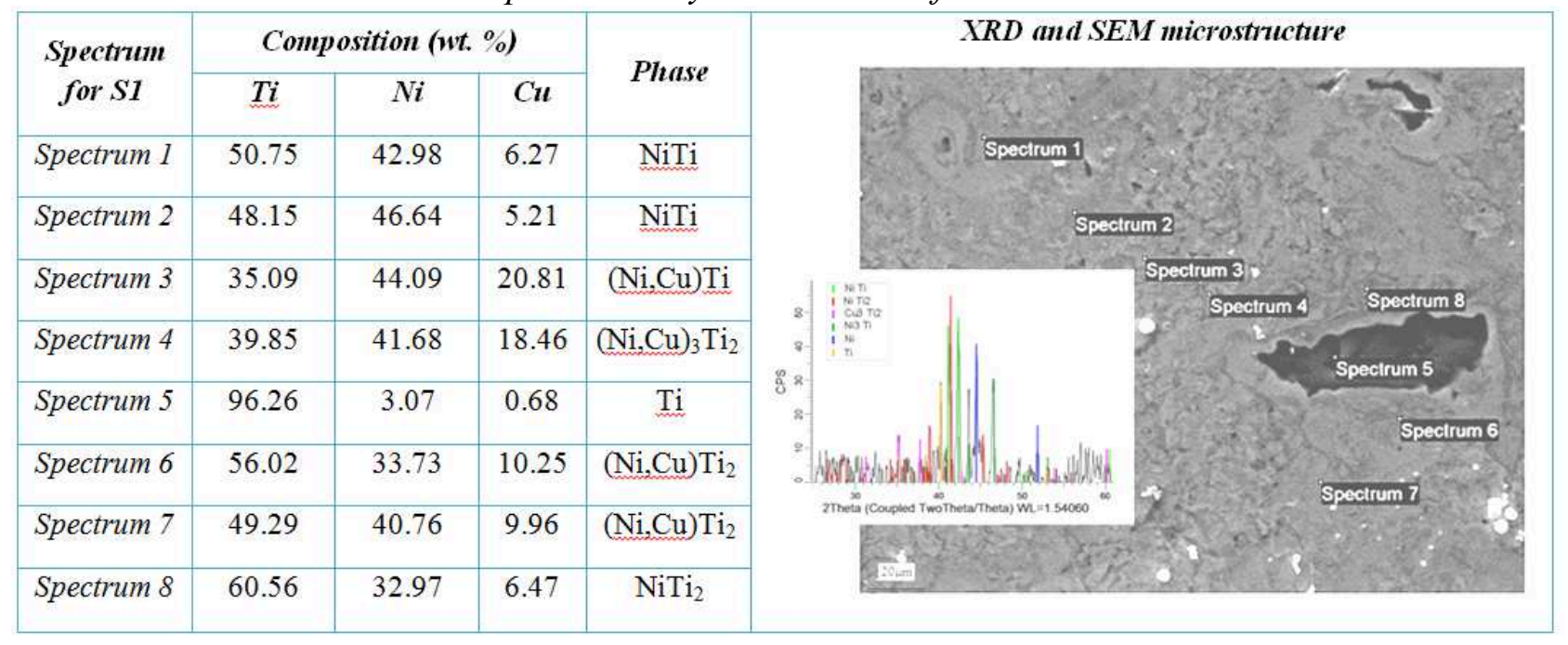

Table 7. EDX results, XRD spectrum and SEM microstructure of NiTiCu sample (S2) processed by $M A$ and SPS

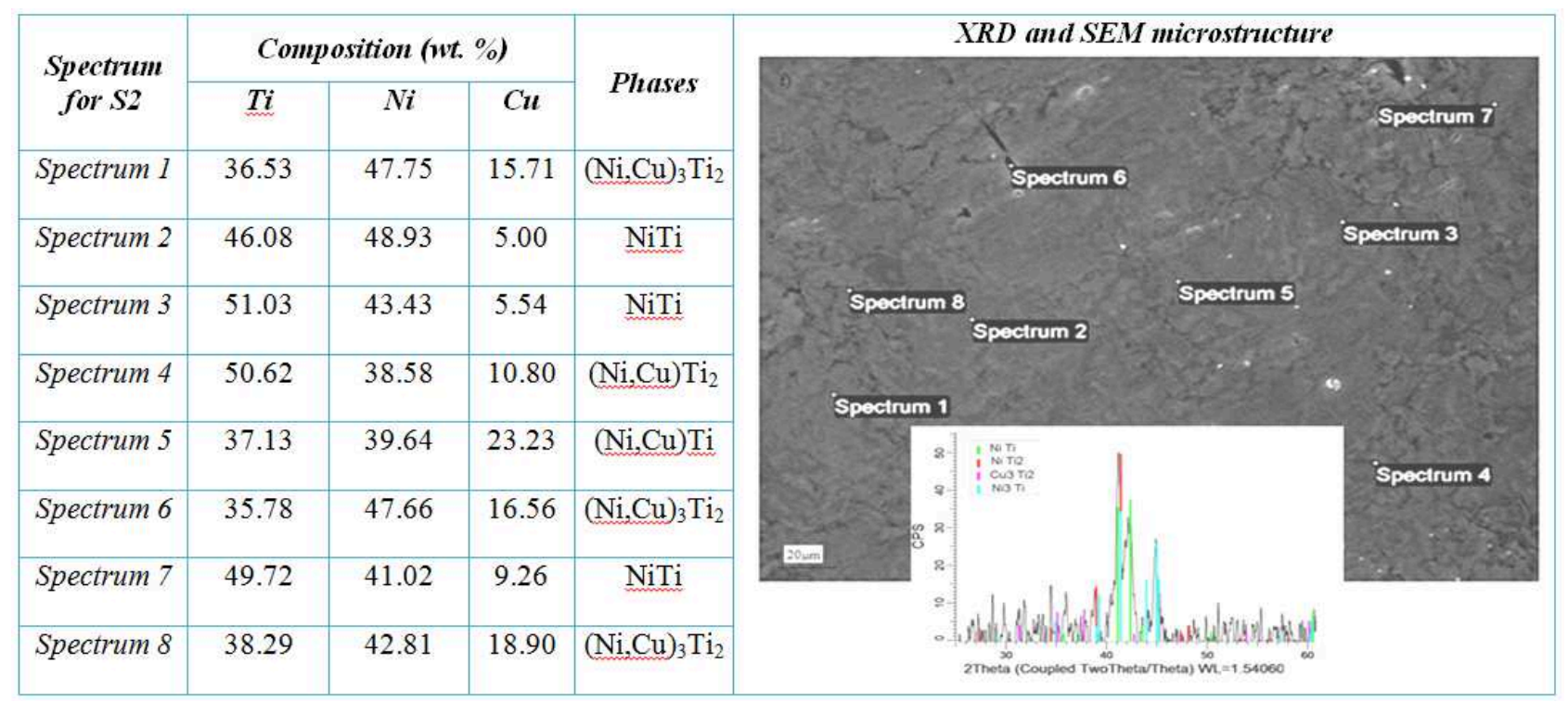




\subsection{Nanoindentation measurements}

The Vickers hardness and Young's modulus values of the NiTi and NiTiCu samples are presented in figure 1 and table 8. Figure 1 shows the evolution of Vickers microhardness (Fig. 1a) and Instrumented Elastic Modulus (EIT) (Fig. 1b), as a function of structural state. Figure 2 shows nanoindentation load $\left(\mathrm{F}_{\mathrm{n}}\right)$ versus penetration depth $\left(\mathrm{P}_{\mathrm{d}}\right)$ curves of the investigated samples.

Table 8. Vickers hardness and Young's modulus of NiTi and NiTiCu samples

\begin{tabular}{|c|c|c|c|c|c|c|}
\hline Sample code & A1 & A2 & B1 & B2 & S1 & S2 \\
\hline $\begin{array}{c}\text { Vickers hardness } \\
\text { (HV) }\end{array}$ & $328 \pm 21.85$ & $266 \pm 14.40$ & $428 \pm 21.75$ & $335 \pm 25.20$ & $803 \pm 17.40$ & $659 \pm 31.11$ \\
\hline $\begin{array}{c}\text { Young's Modulus, } \\
\text { E (GPa) }\end{array}$ & $79 \pm 1.39$ & $84 \pm 3.45$ & $45 \pm 3.30$ & $57 \pm 2.89$ & $95 \pm 4.97$ & $97 \pm 3.83$ \\
\hline
\end{tabular}

The Vickers hardness values increased in case of mechanical alloyed samples B1 and B2, as opposite to the A1 and A2 samples. Similar results for Vickers hardness have been obtained by Y. Zhou et al. have conducted investigations of effect of self-propagating high-temperature combustion synthesis on the deposition of NiTi coating by cold spraying using mechanical alloyed $\mathrm{Ni}, \mathrm{Ti}$ powders [17].
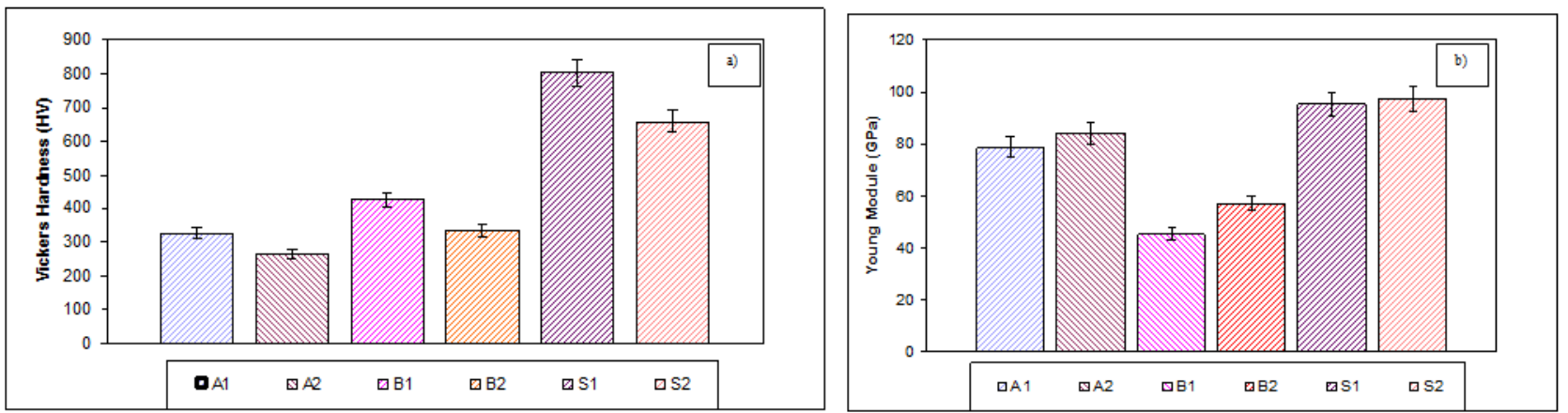

Fig. 1. Calculated nanoindentation parameters of thermomechanical processed alloy; $a$-variation of Vickers microhardness (HV); $b$-variation of Instrumented Elastic Modulus (EIM)

It was also observed that, after the second step of sintering heat treatment, the hardness for A2 and B2 samples decreased compared to the hardness of A1 and B1 samples. The increase in the hardness values by mechanical alloying is mainly attributed to the accumulation of strain energy $[9,16,18]$. Also, it was observed that the material hardness has considerably increased for the samples in which the $\mathrm{Ni}$ was replaced with 10 at. $\% \mathrm{Cu}$.

In the A1, A2, S1 and S2 samples, the Young's modulus determined between 79 and $97 \mathrm{GPa}$ suggests that the materials are predominantly austenitic (Table 8). The B1 and B2 samples have the Young's modulus of 45, respectively $57 \mathrm{GPa}$, which place them to the lower limit of the austenitic type materials [19].

From the shape of the indentation curves (figure 2) it is observed that almost all the samples shows a flatness (linear plateau) during unload, which is associated with the superelastic shape memory materials. The most conclusive results are for the A2 and S2 samples. The superelastic behavior is associated with the existence of precipitate particles in materials microstructure. 

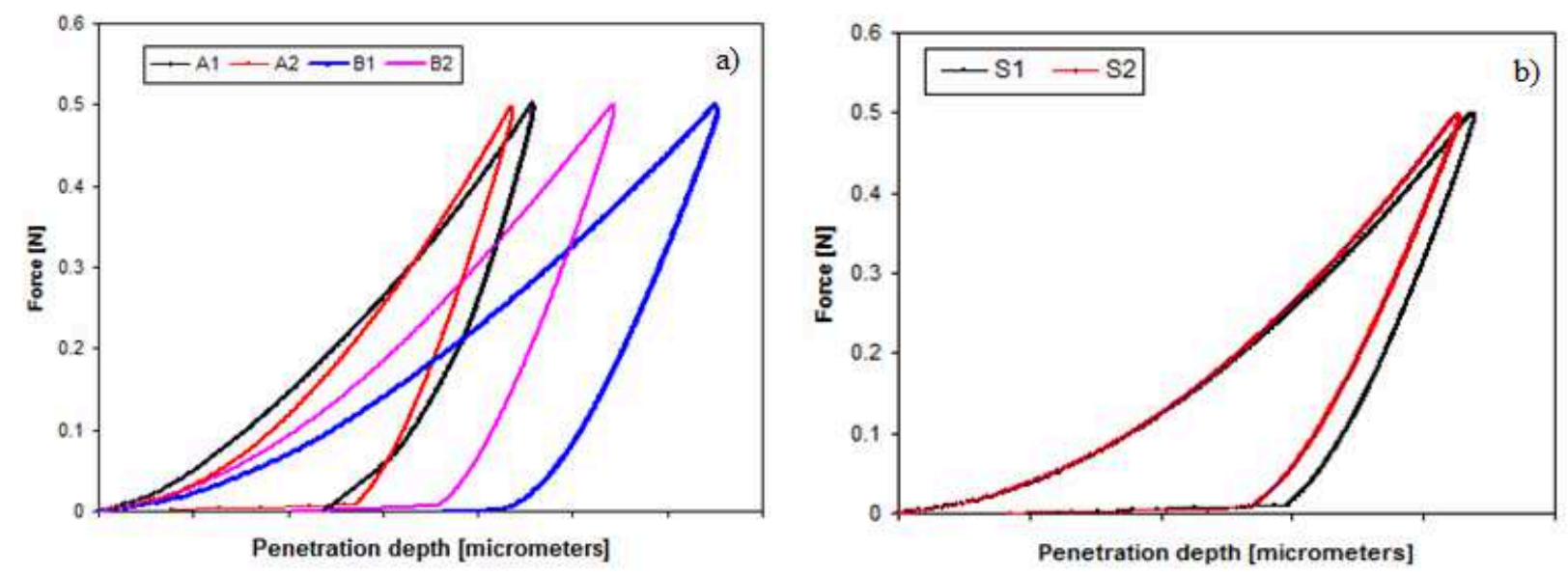

Fig. 2. Nanoindentation load versus penetration depth curves for the NiTi and NiTiCu investigated samples

\section{CONCLUSIONS}

The Vickers hardness values increased in the case of mechanically alloyed B1 and B2 samples, as opposed to the A1 and A2 samples that weren't mechanically alloyed.

The obtained results suggest that the variation in Young's modulus of the NiTi and $\mathrm{NiTiCu}$ alloys is due to the extent of stress-induced phase transformation from austenite to martensite.

Also, it was observed that the NiTi mechanically alloyed material revealed improved characteristics from structural and morphologic point of view. Adding $\mathrm{Cu}$ in NiTi alloy led to the increase of hardness and to the classification of the material as the austenitic type.

\section{Acknowledgements}

This research was supported by the Bilateral Collaboration Romania-Russia under the Projects No. $25 / 2014$.

\section{BIBLIOGRAFY}

[1] K. Otsuka and C.M. Wayman: Shape Memory Materials, 1st ed., Cambridge University Press, Cambridge, U.K., 1998, p. 27.

[2] Duerig T, Pelton A, Stockel D. An overview of Nitinol medical applications. Lausanne: Elsevier Science SA; 1999. p. 149.

[3] C. L. Yeh, W. Y. Sung, Synthesis of NiTi intermetallics by self propagating combustion, Journal of Alloys and Compounds, Vol. 376, Issues 1-2, pp. 79-88, Aug. 2004.

[4] M. Bitzer, M. Bram, H. P. Buchkremer, D. Stöver, Phase Transformation Behavior of Hot Isostatically Pressed NiTi-X $(\mathrm{X}=\mathrm{Ag}, \mathrm{Nb}, \mathrm{W})$ Alloys for Functional Engineering Applications, Journal of Materials Engineering and Performance, Dec. 2012, Vol. 21, Issue 12, pp 2535-2545

[5] C. Shearwood, Y. Q. Fu, L. Yu, K. A. Khor, Spark plasma sintering of TiNi nano-powder, Scripta Materialia, Vol. 52, pp. 455-460, 2005

[6] F. Bernard, S. Le Gallet, N. Spinassou, S. Paris, E. Gaffet, J. N. Woolman, Z. A. Munir, Dense Nanostructured Materials Obtained by Spark Plasma Sintering and Field Activated Pressure Assisted Synthesis Starting from Mechanically Activated Powder Mixtures, Science of Sintering, Vol. 36 (2004), pp. 155-164

[7] Mehulkumar S. Patel, thesis Localized current activated sintering of titanium nickelides, 2011

[8] M. Omori, Sintering, consolidation, reaction and crystal growth by the spark plasma system (SPS), Mater. Sci. Eng A, Vol. 287 (2000) pp. 183-188 
[9] ] Ke Chang, Cao Shan-shan, Ma Xiao, Zhang Xin-ping, modeling of Ni4Ti3 precipitation during stress-free and stress- assisted aging of bi-crystalline NiTi shape memory alloys, Trans Nonferrous Metals Society of China (2012), Vol. 22, pp. 2578-2585.

[10] G. Fan, Y. Zhou, W. Chen, S. Yang, X. Ren, K. Otsuka, Precipitation kinetics of $\mathrm{Ti}_{3} \mathrm{Ni}_{4}$ in polycrystalline Ni-rich TiNi alloys and its, relation to abnormal multi-stage transformation behavior, Materials Science and Engineering (2006) 622-626

[11] N. Zhou et al.,Acta Materialia 58 (2010) pp 6685-6694

[12] Y. Sugo, H. Hasegawa, T. Honma, Bull. Res. Inst. Mineral Dress. Metall. Tohoku Univ. 1981, 37, pp. 79-88

[13] Oliver, W.C.; Pharr, G.M. Improved technique for determining hardness and elastic modulus using load and displacement sensing indentation experiments. J. Mater. Res. 1992, 7 (6), 15641583

[14] Neves F, Martins I, Correia JB, Oliveira M, Gaffet E. Reactive extrusion synthesis of mechanically activated $\mathrm{Ti}-50 \mathrm{Ni}$ powders. Intermetallics 2007;15:1623-31

[15] F. Alijani, R. Amini, M. Ghaffari, M. Alizadeh, A K Okyay, Effect of milling time on the structure, micro-hardness, and thermal behavior of amorphous/nanocrystalline TiNiCu shape memory alloys developed by mechanical alloying, Materials and Design 55 (2014) 373-380

[16] Valeanu M, Lucaci M, Crisan AD, Sofronie M, Leonat L, Kuncser V. Martensitic transformation of $\mathrm{Ti}_{50} \mathrm{Ni}_{30} \mathrm{Cu}_{20}$ alloy prepared by powder metallurgy. $\mathrm{J}$ Alloys Compd 2011;509:4495-8

[17] Y. Zhou, Ch. Li, G. Yang, H. Wang, G. Li, Effect of self-propagating high-temperature combustion synthesis on the deposition of NiTi coating by cold spraying using mechanical alloying $\mathrm{Ni}$ /Ti powder, Intermetallics 18 (2010) 2154-2158.

[18] Suryanarayana C, Klassen T, Ivanov E. Synthesis of nanocomposites and amorphous alloys by mechanical alloying. J Mater Sci 2011;46:6301-15

[19] http://en.wikipedia.org/wiki/Nickel_titanium 